\title{
Molecular phylogenetic estimates of evolutionary affinities and the first reports of phenotypic variation in two secretive, endemic reptiles from the Romblon Island Group, central Philippines
}

\author{
Camila G. Meneses ${ }^{1,2, *}$, Cameron D. Siler ${ }^{3,4}$, Juan Carlos T. Gonzalez ${ }^{1,2}$, Perry L. Wood, Jr. ${ }^{5,6}$, \\ and Rafe M. Brown ${ }^{6}$
}

\begin{abstract}
We report on the first molecular estimates of phylogenetic relationships of Brachymeles dalawangdaliri (Scincidae) and Pseudogekko isapa (Gekkonidae), and present new data on phenotypic variation in these two poorly known taxa, endemic to the Romblon Island Group of the central Philippines. Because both species were recently described on the basis of few, relatively older, museum specimens collected in the early 1970s (when preservation of genetic material was not yet standard practice in biodiversity field inventories), neither taxon has ever been included in modern molecular phylogenetic analyses. Likewise, because the original type series for each species consisted of only a few specimens, biologists have been unable to assess standard morphological variation in either taxon, or statistically assess the importance of characters contributing to their diagnoses and identification. Here we ameliorate both historical shortfalls. First, our new genetic data allowed us to perform novel molecular phylogenetic analyses aimed at elucidating the evolutionary relationships of these lineages; secondly, with population level phenotypic data, from the first statistical sample collected for either species, and including adults of both sexes. We reaffirm the distinctiveness of both named taxa as valid species, amend their diagnoses to facilitate the recognition of both, distinguish them from congeners, and consider the biogeographic affinities of both lineages. Our contribution emphasizes the conservation significance of Sibuyan Island's Mt. Guiting-Guiting Natural Park, the diverse, idiosyncratic biogeographic histories of its variably-assembled, highly endemic reptile fauna, and the critical importance of multiple, repeated, survey-resurvey studies for understanding forest community species composition and the evolutionary history of Philippine biodiversity.
\end{abstract}

Keywords: biodiversity, endemism, forest geckos, faunal region, fossoriality, limb reduction

\footnotetext{
${ }^{1}$ University of the Philippines Los Baños Museum of Natural History, Los Baños, Laguna, 4031, Philippines

${ }^{2}$ Institute of Biological Sciences, Animal Biology Division, University of the Philippines, Los Baños, College, Laguna, 4031, Philippines

3 Department of Biology, University of Oklahoma, Norman, OK, 73019, USA

${ }^{4}$ Sam Noble Oklahoma Museum of Natural History, University of Oklahoma, Norman, OK, 73072-7029, USA

${ }^{5}$ Department of Biological Sciences \& Museum of Natural History, Auburn University, Auburn, AL, 36849, USA

${ }^{6}$ Biodiversity Institute and Department of Ecology and Evolutionary Biology, University of Kansas, Lawrence, KS, 66045, USA

*Corresponding email: camilagmeneses23@gmail.com

Date Submitted: 23 October 2019

Date Accepted: 01 June 2020
}

\section{Introduction}

Sibuyan Island, in the central Philippine Romblon Island Group (RIG; Figs. 1, 2A, B) is regarded as one of the archipelago's unique centers of biological diversity owing to its geologic history and biogeographically amalgamate fauna, derived from over-water colonization from multiple faunal regions (Goodman and Ingle 1993, Goodman et al. 1995, Siler et al. 2012a). A high proportion of the region's fauna and flora are recognized as distinct due to its geographic isolation; the RIG landmasses have never been connected to other surrounding islands despite being located centrally among three major faunal regions (Luzon, Mindoro, and West Visayan Pleistocene Aggregate Island Complexes [PAICs; Brown and Diesmos 2009, Siler et al. 2012a, Brown et al. 2013, Fig. 1]. Also the RIG's largest island, Sibuyan, is characterized by 


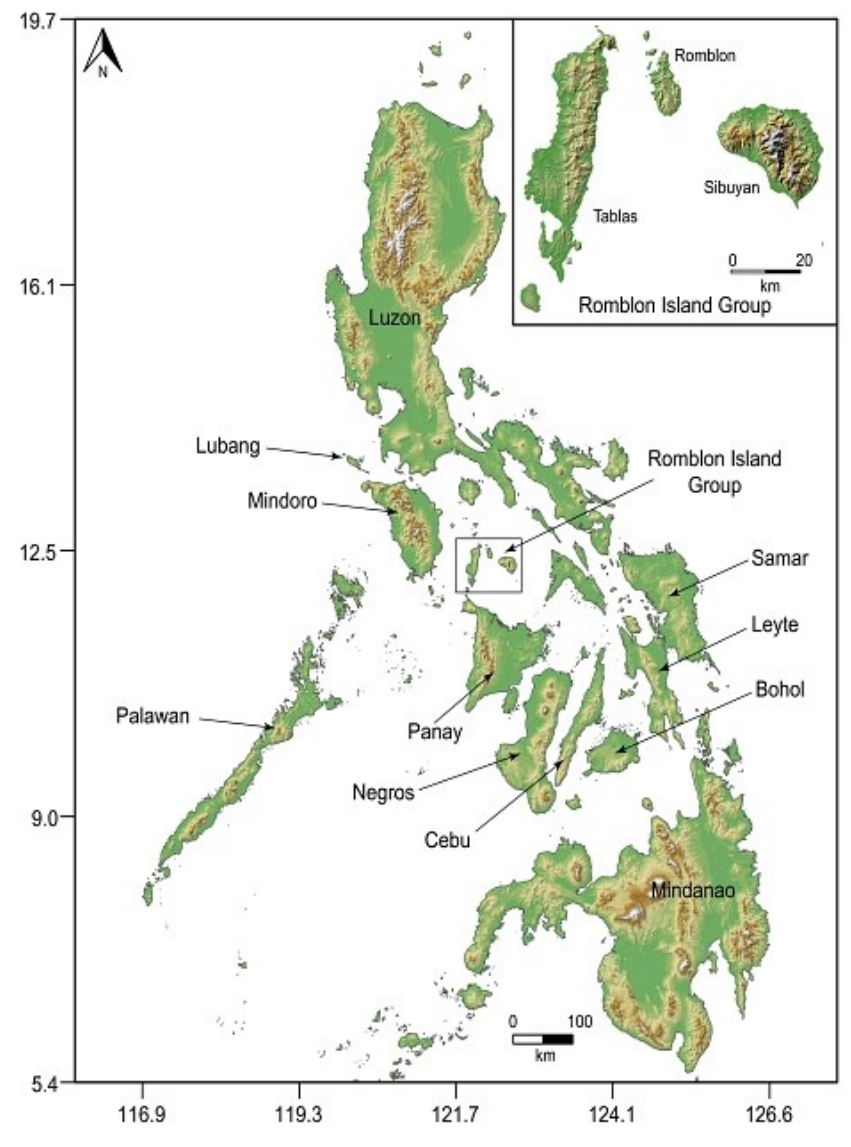

Figure 1. Map of the Philippines showing the five recognized major Pleistocene Aggregate Island Complexes (PAICs) and additional deep -water islands in the Philippines. The location of Romblon Province in the central Philippines is outlined by a box (upper right).

considerable topographic relief and high elevation montane forest habitats that provide environmental/atmospheric gradients (temperature, precipitation, etc.), which greatly contribute to the diverse land vertebrate assemblage supported by this small island of roughly $445 \mathrm{~km}^{2}$ in area (Goodman et al. 1995, Hall 1998, Heaney and Regalado 1998, Steppan et al. 2003, Esselstyn and Goodman 2010, Siler et al. 2012a, 2016).

The first herpetological surveys and faunal collections from Sibuyan Island were conducted in 1972 by L.C. Alcala (Brown and Alcala 1974, 1978); some specimens from that expedition were used to describe endemic new species of amphibians (Platymantis levigatus and Platymantis lawtoni; Brown and Alcala 1974), and others were reported in faunal lists, but identified as members of widespread polytypic species (Brown and Alcala 1970, 1978, 1980). Other species, represented until recently by a few specimens from these initial 1970s surveys, were later recognized as new endemic species. These include the recently-described Gekko coi from Sibuyan Island and a putative new species of Platymantis (Brown et al.
2011, 2015, Siler et al. 2012b). In contrast, perhaps due to their rarity, elusiveness, secretive behavior, the recently described RIG endemic lizards, Brachymeles dalawangdaliri and Pseudogekko isapa (Davis et al. 2016, Siler et al. 2012b, 2016) have remained unsampled for genetic material and have never been included in molecular phylogenetic analyses.

The genus Brachymeles is a predominantly endemic Philippine radiation of cryptic and semi-fossorial lizards. The genus has 42 recognized Philippine species, 40 of which are endemic to the archipelago (Davis et al. 2014, 2016, Geheber et al. 2016, Siler et al. 2016, this publication). Over the past decades, a notable $220 \%$ increase of recognized species diversity across the Philippine archipelago was characterized because of a renewed effort at understanding evolutionary processes underlying phenotypic and geographic patterns of diversification (Taylor 1917, Brown 1956, Brown and Rabor 1967, Brown and Alcala 1980, Siler et al. 2009, 2010a,b, 2011a -d, 2012a, Siler 2010, Siler and Brown 2010). Despite this concerted effort, there are species that, to date, are known only from few specimens in collections $(<10$ specimens $)$ and, thus, remain poorly understood.

Davis et al. (2016) described Brachymeles dalawangdaliri based on a small series of five adult females and two adult males collected in 1972 from Barrio Dubduban, municipality of San Agustin, Tablas Island. Nearly 50 years ago, the Tablas population was considered part of the poorly understood Brachymeles bonitae Complex, which spanned multiple faunal regions (Siler et al. 2012b). This underrepresented newly described species was differentiated based on a suite of unique phenotypic characters such as small body size, bidactyl forelimbs, digitless, unidactyl, or bidactyl hindlimbs, a high number of presacral vertebrae $(\mathrm{n}=49)$, absence of auricular openings, and distinct dorsal head scale patterns.

In the same year, Siler and colleagues described a new species of lizards in the genus Pseudogekko from the islands of Tablas and Sibuyan (Siler et al. 2016). As in B. dalawangdaliri, Pseudogekko isapa is conspicuously rare in collections and completely unstudied in its natural habitat (Siler et al. 2009, Siler and Brown 2010). Phenotypically, the only known population was allied with the Pseudogekko compresicorpus Complex, making it the $7^{\text {th }}$ recognized species of False Gecko (aka Philippine Forest Geckos) in the Philippines - but also one of the archipelago's most poorly-known species in this genus. Siler et al. (2016) defined P. isapa based on the only two specimens ever collected: one from Tablas, collected 50 years ago by L.C. Alcala, and the other collected near Mt. GuitingGuiting Natural Park (Diesmos, 2014; personal communication). This new, seemingly rare obligate forest species was distinguished by the combination of its body size 
and shape, color pattern, multiple differences in scale characteristics; its recognition as a distinct evolutionary lineage was supported by inferences of the geological history of the RIG (Yumul et al. 2009a, b, Aurelio et al. 2013, Siler et al. 2016).

In summary, despite recently renewed herpetological survey efforts, combined with phylogenetic analyses of molecular data and expanded summaries of phenotypic variation that have resulted in substantial increases in species diversity in the genera Brachymeles and Pseudogekko over the last decades (Siler et al. 2010a, 2012b, 2016, Brown et al. 2013), limitations posed by small sample sizes available in museum collections have impeded efforts to assess species-level diversity comprehensively in these endemic Philippine species.

Here we ameliorate some of these historical shortcomings by reporting on new genetic and morphological data, which allow for statistical characterization of intraspecific variation, estimates of phylogenetic relationships, inference of biogeographic affinities, and interspecific comparisons with congeners in $B$. dalawangdaliri and $P$. isapa for the first time. The goal of this study is to provide an improved understanding of genetic and morphological variation in these two secretive RIG endemic reptile species, based on a more comprehensive examinations of the most recent available specimens and newlyobtained genetic data.

\section{Materials and Methods}

\section{Fieldwork, sample collection, and specimen preservation}

Fieldwork was conducted on Sibuyan Island in the Philippines, between October-November, 2016 and May-June, 2017 (Figs. 2A, B). Specimens were collected, euthanized with
$10 \%$ diluted alcohol, dissected for tissue samples (liver preserved in $100 \%$ ethanol), fixed in $10 \%$ buffered formalin, and eventually ( $<2$ months) transferred to $70 \%$ ethanol for longterm storage. New specimens contributing to this report are deposited in University of the Philippines Los Baños Museum of Natural History (UPLB-MNH), Philippines (see Appendix I). Museum abbreviations for specimens examined follow those from Sabaj (2016).

\section{DNA Sequence Data}

Total genomic DNA was extracted from newly -collected genetic material with a Maxwell ${ }^{\circledR}$ RSC Tissue DNA kit and a Promega Maxwell® RSC extraction robot at the University of Kansas Biodiversity Institute's Molecular Genomics Laboratory. Previously published Pseudogekko and Brachymeles sequences for the mitochondrial NADH dehydrogenase subunit 2 gene (ND2) are available on GenBank (see Davis et al. 2014; Siler et al. 2014a) and were downloaded for this study. We amplified and collected matching ND2 sequence data from one vouchered individual of Brachymeles dalawangdaliri (UPLB-MNH-Z-NS 4853) and seven individuals of Pseudogekko isapa (UPLBMNH-Z-NS 4606, 4610, 4614, 4615, 4617, 4618, 4620). Primers and protocols for all sequencing efforts follow Davis et al. (2014) for Brachymeles and Siler et al. (2014a) for Pseudogekko. Novel sequences are deposited at GenBank (Accession Nos. MT 840340-840346).

\section{Alignment and Phylogenetic Analysis}

We outsourced PCR products (visualized on 1.0\% agarose gels) to GENEWIZ® for purification, cycle sequencing, and sequence determination. We sequenced target regions in both directions and confirmed congruence in Geneious version R11

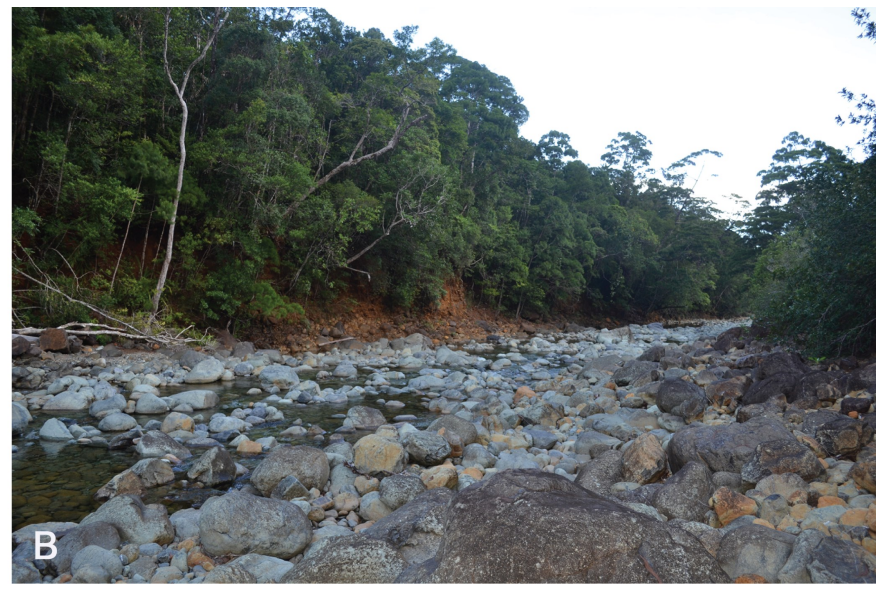

Figure 2. (A) View of Mt. Guiting-Guiting Natural Park, from the foothills in the buffer zone area. (B) Typical characteristics of lowelevation riverside vegetation in Mt. Guiting-Guiting Natural Park. Photos by CGM. 
(https://www.geneious.com/). The ND2 protein-coding regions of the newly collected sequence datasets were aligned to available, Brachymeles and Pseudogekko ND2 data using the MAFTT v7.017 (Katoh and Standley 2013) plugin under GeneiousTM defaults. For analyses of Pseudogekko, we also included sequences of geckos in the genera Cyrtodactylus, Gehyra, and Luperosaurus from GenBank as outgroups based on results of several previous phylogenetic studies of Pseudogekko (Siler et al. 2014a); for analyses of Brachymeles, we included sequences of lizards in the genera Tachydromus, Plestiodon, Dasia, Eutropis, and Lygosoma from GenBank as outgroups based previous phylogenetic studies of Davis et al. (2014) and Wagner et al. (2009). A total of 50 and 41 samples were used in the phylogenetic analyses of Pseudogekko and Brachymeles, respectively.

The protein-coding region of ND2 was partitioned by codon positions and best-fit models of molecular evolution were estimated using ModelFinder (Kalyaanamoorthy et al. 2017) in IQ-TREE (Nguyen et al. 2015, Trifinopoulos et al. 2016) using the Bayesian Information Criterion (BIC). We ran partitioned, Maximum Likelihood analyses in W-IQ-TREE (Nguyen et al. 2015, Trifinopoulos et al. 2016) and assessed nodal support via 1,000 bootstrap pseudoreplicates using the ultrafast approximation algorithm (Minh et al. 2013). All nodes with ultrafast bootstrap values (UFBs) of $\geq 95$ were considered significantly supported (Minh et al. 2013).

\section{Morphological data}

Measurements were taken to the nearest $0.1 \mathrm{~mm}$ with digital calipers and the sex of each specimen was determined by gonadal inspection. The following measurements were taken by RMB and CGM. Meristic (scale counts) and mensural (measurements) characters were taken from newly collected, fluid-preserved specimens following the character descriptions and definitions of Siler et al. (2009, 2010a,b) for Brachymeles dalawangdaliri: snout-vent length (SVL), axilla-groin distance (AGD), total length (TotL), midbody width (MBW), midbody height (MBH), tail length (TL), tail width (TW), head length (HL), head width (HW), eye-diameter (ED), eye- nares distance (END), snout length (SNL), fore-limb length (FLL), hind-limb length (HLL), midbody scale row count (MBSR), paravertebral scale-row count (PVSR), axilla-groin scale-row count (AGSR), supralabial count (SL), infralabial count (IFL), supraciliary count (SC), and supraocular count (SO); prefrontal contact; frontoparietal contact; $1^{\text {st }}$ chin shield pair medial contact; $3^{\text {rd }}$ chin shield pair presence, contact; mental $/ 1^{\text {st }}$ infralabial scale fusion presence; enlarged nuchal presence; and longitudinal rows of dark spots along the body presence.
Morphological data for Pseudogekko isapa were chosen based on Siler et al. (2014b, 2016) and Davis et al. (2015): snout -vent length (SVL); total length (TotL); tail length (TL); tail width (TW), tail depth (TD), head length (HL), head width (HW), midbody width (MBW), snout length (SNL), eye diameter (ED), eye nares diameter (END), internarial distance (IND), inter-orbital distance (IOD), axilla-groin distance, (AGD) femur length (FL), tibia length (TibL),supralabials (SL), infralabials (IL), circumorbitals, precloacal scale count, FingerIII scansors, Toe-IV scansors, midbody scale count, paravertebral scale counts (PVSC), and ventrals scale count.

\section{Results}

\section{New records}

As part of a standardized elevational transect aimed at quantifying diversity, abundance and community composition of amphibians and reptiles along Mt. Guiting-Guiting's elevational relief (Meneses 2018), population-level sampling (adult males, females, and juveniles) of specieswere obtained, including new site and microhabitat records for Brachymeles dalawangdaliri and Pseudogekko isapa (Fig. 3A-F).

From October-November, 2016 and May-June, 2017, three adult males (213-405 $\mathrm{m}$ above sea level [masl]: UPLBMNH-Z-NS 4850, 4853, and 4854) and four adult females (576939 masl: UPLB-MNH-Z-NS 4848, 4849, 4851, and 4852; 10 148 masl: UPLB-MNH-Z-NS 4852) of $B$. dalawangdaliri were collected during herpetological field surveys in low- to midelevation forest of Mt. Guiting-Guiting Natural Park, municipality of Magdiwang, Sibuyan Island, Philippines. We follow Goodman et al. (1995) and consider elevational ranges of 10-405 masl as lowland and those of 576-939 masl as montane forest types. The new specimens of $B$. dalawangdaliri were collected under large boulders of ultramafic rocks, forest floor detritus, and rotting logs. This species has never been observed in high densities and little is known of its ecological preferences or preferred microhabitats.

During our field surveys, five adult males (41-55 masl: UPLB-MNH-Z-NS 4614; 576-939 masl: UPLB-MNH-Z-NS 4606, 4609, 4612, and 4615), eight adult females (213-405 masl: UPLB-MNH-Z-NS 4617-4620; 576-939 masl: UPLBMNH-Z-NS 4608-4611, 4616), and two juveniles (41-55 masl: UPLB-MNH-Z-NS 4613; 576-939 masl: UPLB-MNH-Z-NS 4607) of Pseudogekko isapa were collected. A total of 15 new vouchered specimens were collected from low- to midelevation forests of Sibuyan. This enigmatic gekkonid is primarily a forest obligate species; additional specimens were collected from high-quality secondary forests of Mt. GuitingGuiting Natural Park. Like B. dawalangdaliri, little is known 

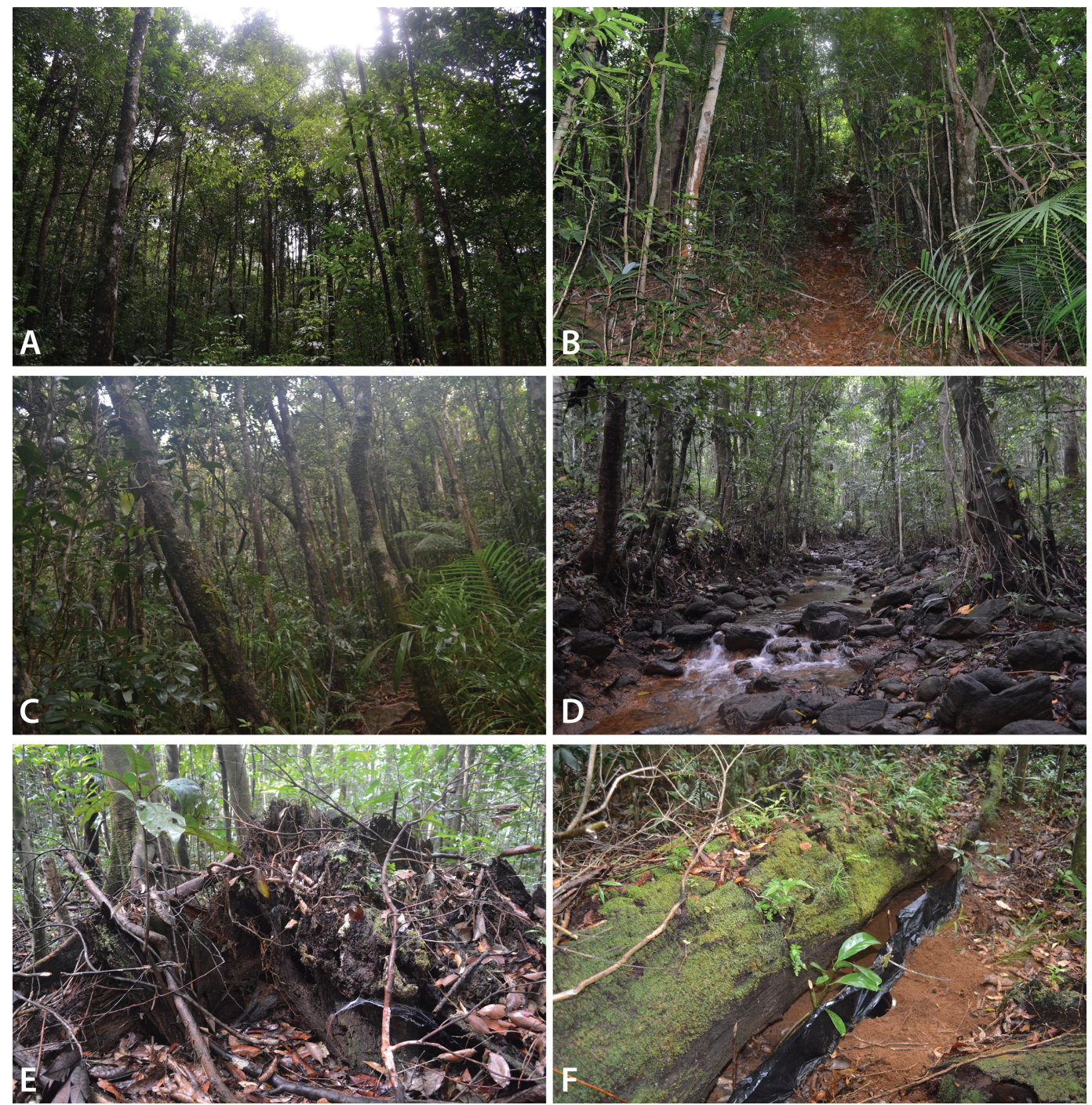

Figure 3. Photographs of forested microhabitat variation in Mt. Guiting-Guiting Natural Park: (A-C) Forest view from a ridge, approximately 326-900 masl, Mt. Guiting-Guiting Natural Park, Sitio Logdeck, Barangay Tampayan, Municipality of Magdiwang. (D) Small forested stream near the station house at the buffer zone area. (E-F) Dead tree trunk and rotten log habitats at approximately 326-700 masl. Photos by CGM.

about the species' microhabitat preferences. However, our new specimens were observed in varied microhabitat types such as small vines hanging above the streams, 3-5 $\mathrm{m}$ above the ground in shrubs, and on the trunk of a dipterocarp tree $(>120 \mathrm{~cm}$ $\mathrm{DBH})$. Like $B$. dawalangdaliri, there still exists a general paucity of information about the habitat requirements of this rare RIG endemic species.

\section{Morphological variation, coloration, and partial redescriptions}

Brachymeles dalawangdaliri Davis, Geheber, Watters, Penrod, Feller, Ashford, Kouri, Nguyen, Shauberger, Sheatsley, Winfrey, Wong, Sanguila, Brown \& Siler, 2016

Davis et al. (2016) provided the first description of
Brachymeles dalawangdaliri based on collections made nearly 50 years ago. It was described in reference of its highly distinctive external characteristics of having two digits on the fore-limbs. The species was last documented in 1972 based on all the available museum specimens used by Davis et al. (2016). There are only seven published vouchered records of $B$. dalawangdaliri (Holotype: CAS 137149 and Paratype: CAS 137148, 137150, 137151, 137153, 137154, 137152, inspected and verified by CDS). The type specimens of the species are known only from Barrio Dubduban, municipality of San Agustin, Tablas Island in the RIG (Alcala, 1972). Interestingly, five females and three male adult individuals were collected in 2018 from Mt. Guiting-Guiting Natural Park, Sitio Logdeck, Baranagy Tampayan, municipality of Magdiwang on Sibuyan 
Island. The addition of $B$. dalawangdaliri increases the number of restricted endemic species of RIG (Davis et al. 2016). Herein, we review and re-describe the species based on the type specimens and eight referred specimens.

Variation: Meristic and mensural characters of the newly discovered populations of this unique radiation of cryptic and semi-fossorial skinks from Sibuyan Island are consistent with the recognized diagnostic characters for $B$. dalawangdaliri (Table 1). No character variation was observed between the Tablas and Sibuyan Island populations. Notably, tail length, a character not emphasized by Davis et al. (2016) due to the unavailability of intact tail of the museum specimens, was documented (Total length: $120.5-133.8 \mathrm{~mm}, 127.2 \pm 9.4$ ). All diagnostic characters for $B$. dalawangdaliri were observed to match the type specimens.

Coloration in life: Body coloration in life is consistent with the characterized preserved coloration; the ground color on the dorsal, lateral, and ventral aspects of the body is a solid Prout's Brown (Color 47; Köhler 2012) and the same solid color was observed in the ventral side of the head. On the dorsal and lateral sides of the head, the same color description provided by Davis et al. (2016) of a single Fuscous splotch above each orbit can be seen (Color 283; Köhler 2012). Photographs in life showed typical representation of the novel variation of pigmentation, as described, that may facilitate species field identification (Figs. 4A, B.1, B.2).

Partial redescriptions: Measurements of the congeners described by Davis et al. (2016) are shown in brackets. Recent collections can be distinguished from its congeners by the following combination of characters: (1) body size small (52$66.0 \mathrm{~mm} \mathrm{SVL}$ ) [66.0-80.9 mm]; (2) fore-limbs and hind limbs bidactyl; (3) limb length short (1.2-2.2 mm FLL, 1.4-2.1 mm HLL) [1.4-2.2 mm FLL, 1.9-2.2 mm HLL]; (4) supralabials five or six [six or seven]; (5) infralabials five or six [six or seven]; (6) supraciliaries four [five], (7) supraoculars four [five]; (8) midbody scale rows 24-28 [24 or 25]; (9) axillagroin scale rows 85-89 [80-83]; (10) paravertebral scale rows 102-108 [97-101]; (11) prefrontal contact absent; (12) frontoparietal contact absent; (13) $1^{\text {st }}$ and $3^{\text {rd }}$ chin shield medial contact absent; and (14) uniform body color.

Further description based on holotype (in brackets) and new samples showed that the new specimens have the same small and slender body; head weakly differentiated from neck, nearly as wide as the body; HW 6.10-7.44\% SVL [7.9\%], 78.18 $-100.0 \%$ HL [107.3\%]; snout narrow, sharply rounded in dorsal and lateral aspects, SNL 54.5-60.34\% [60.2\%] HL; eyes small, ED 15.63-20.69\% HL[17.9\%], 38.46-48\% END [40.5\%], pupil subcircular; body slightly depressed exhibiting uniform thickness, MBW 100.0\% MBH [100.0\%]; FLL 2.04-4.08\%
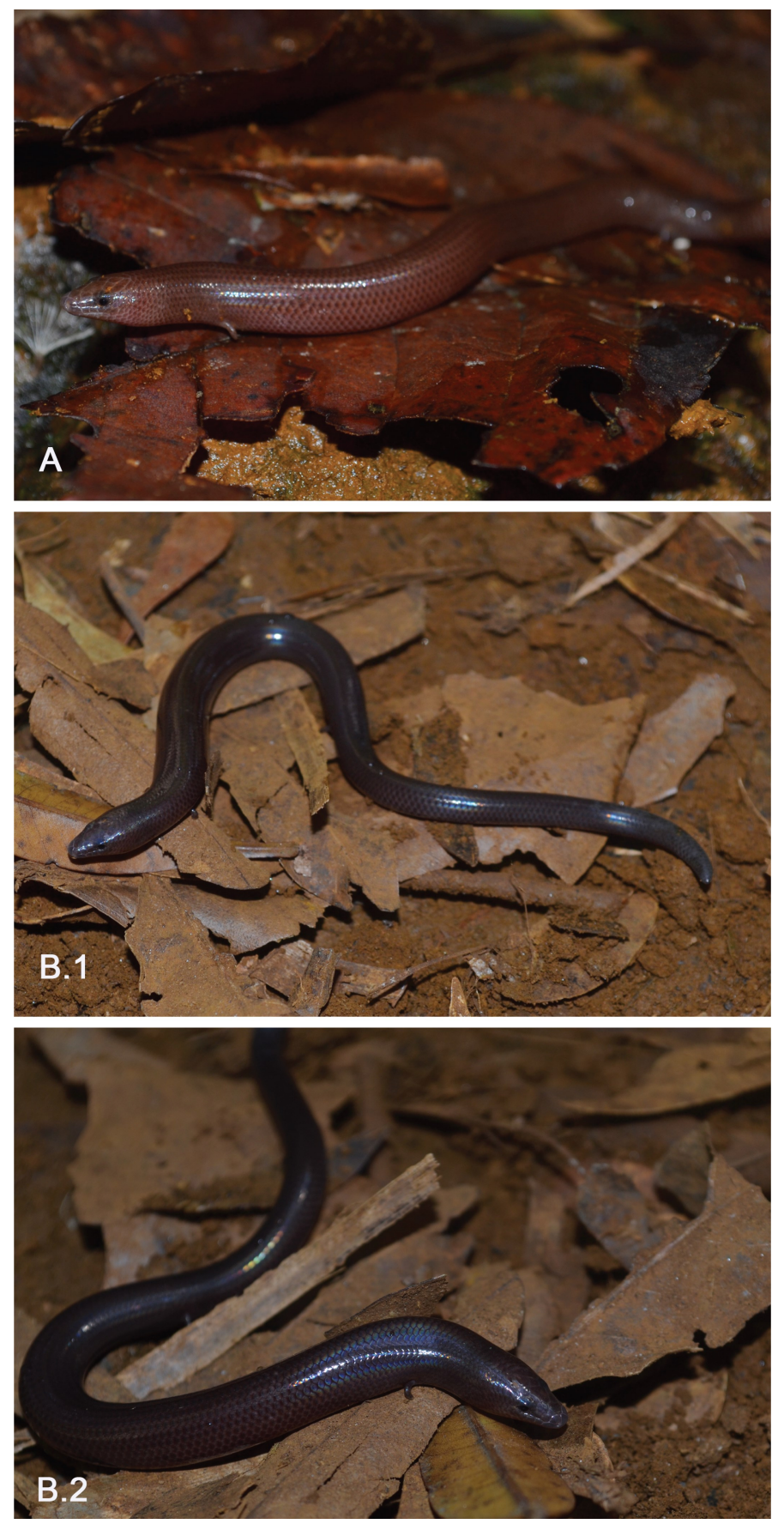

Figure 4. Typical appearance in life of Brachymeles dalawangdaliri, (A) UPLB-MNH-Z-NS 4848; (B.1-B.2) UPLB-MNH-Z-NS 4850. Photos by CGM.

AGD [3.6\%], 1.56-2.99\% SVL [2.8\%]; HLL 2.26-4.05\% AGD [3.9\%], $1.71-3.03 \%$ SVL [3.0\%]; tail as wide as body, TW 81.25-100.0\% MBW [72.6\%], TotL $120.5-133.8 \mathrm{~mm}$ [autotomized posterior to cloaca].

Pseudogekko isapa Siler, Davis, Diesmos, Guinto, Whitsett, and Brown, 2016 
Table 1. Summary of representative meristic and mensural characters among adult specimens from the newly expanded, vouchered collections of Brachymeles dalawangdaliri. Mensural characters are given in $\mathrm{mm}$ as a range followed by mean \pm standard deviation in parentheses where sample size allows and are given as individual values otherwise. In cases of scale count variation within species, numbers of individuals showing specific counts are given in parentheses.

\begin{tabular}{|c|c|c|}
\hline & $\begin{array}{l}\text { dalawangdaliri } \\
\text { Davis et al. (2016) }\end{array}$ & $\begin{array}{c}\text { dalawangdaliri } \\
\text { Sibuyan Island (newly collected series) }\end{array}$ \\
\hline Sample size (female, male) & 5,2 & 4,3 \\
\hline \multirow[t]{2}{*}{ SVL (female) } & $69.8-80.9$ & $52.0-65.8$ \\
\hline & $(73.6 \pm 4.4)$ & $(61.5 \pm 5.5)$ \\
\hline \multirow[t]{2}{*}{ SVL (male) } & $66.0-74.9$ & $54.7-66.0$ \\
\hline & $(70.4 \pm 6.3)$ & $(61.2 \pm 4.2)$ \\
\hline \multirow[t]{2}{*}{ Total length } & - & $120.5-133.8$ \\
\hline & & $(127.2 \pm 9.4)$ \\
\hline \multirow[t]{2}{*}{ Tail length/SVL } & - & $54-56$ \\
\hline & & $(55 \pm 1)$ \\
\hline \multirow[t]{2}{*}{ Fore-limb length } & $1.4-2.2$ & $1.2-2.2$ \\
\hline & $(1.9 \pm 0.3)$ & $(1.7 \pm 0.3)$ \\
\hline \multirow[t]{2}{*}{ Fore-limb length/SVL } & $2-3$ & $2-3$ \\
\hline & $(3 \pm 0)$ & $(2 \pm 1)$ \\
\hline \multirow[t]{2}{*}{ Hind limb length } & $1.9-2.2$ & $1.4-2.1$ \\
\hline & $(2.1 \pm 0.1)$ & $(1.9 \pm 0.2)$ \\
\hline \multirow[t]{2}{*}{ Hind limb length/SVL } & $2-3$ & $2-3$ \\
\hline & $(3 \pm 0)$ & $(3 \pm 0)$ \\
\hline Number of digits (fingers/toes) & $2 / 0-2$ & $2 / 2$ \\
\hline Presacral vertebrae count & 49 & - \\
\hline Midbody scale row count & 24,25 & $24-28$ \\
\hline Axilla-groin scale row count & $80-83$ & $85-89$ \\
\hline Paravertebral scale count & $97-101$ & $102-108$ \\
\hline \multirow[t]{2}{*}{ Supralabial count } & $6(3)$ & $5(4)$ \\
\hline & $7(4)$ & $6(3)$ \\
\hline \multirow[t]{2}{*}{ Infralabial count } & $6(3)$ & $5(1)$ \\
\hline & $7(4)$ & $6(6)$ \\
\hline Supraciliary count & 5 & 4 \\
\hline Supraocular count & 5 & 4 \\
\hline Prefrontal contact & Absent & Absent \\
\hline Frontoparietal contact & Present or Absent & Absent \\
\hline $1^{\text {st }}$ chin shield pair contact & Absent & Absent \\
\hline $3^{\text {rd }}$ chin shield pair & Absent & Absent \\
\hline Mental $/ 1^{\text {st }}$ infralabial fusion & Absent & Absent \\
\hline
\end{tabular}

-, Total length not available without intact original tail. 
Siler et al. (2016) described Pseudogekko isapa in reference to their surprise at the discovery of another highly distinctive new species of Pseudogekko from the RIG. This recent discovery resulted from the comprehensive revised systematic study of the two major Pseudogekko complexes, the P. compresicorpus Complex (Siler et al. 2014a) and the $P$. brevipes Complex (Davis et al. 2015). Since it was last documented, there were only two published vouchered records of $P$. isapa in Romblon province (Holotype: PNM 9816 and Paratype: CAS 139713, inspected and verified by CDS). The holotype specimen was collected from Mt. Guiting-Guiting Natural Park, Baranagy Talaba, municipality of Magdiwang (personal communication with A.C. Diesmos, 2014) and the paratype was collected from Barrio Dubduban, municipality of San Agustin on Tablas (Alcala, 1972). Remarkably, eight females and five male adult individuals were collected during the most recent field expedition in 2017. Two juveniles of undetermined sex were also collected. The 13 adult specimens were collected from Mt. Guiting-Guiting Natural Park, Sitio Logdeck, Barangay Tampayan, municipality of Magdiwang on Sibuyan.

Variation: Measurements and scale counts of the two type specimens are shown in brackets. Based on measurements of the adult individuals, the new samples from Sibuyan Island can be distinguished from the type specimens by the following combination of characters: (1) body moderately large, elongate, slender, SVL 52.0-65.8 mm (females), 54.7-66.0 mm (males) [62.1, 63.4]; (2) AGD 27.1-37.4 mm, $33.0 \pm 3.8$ [32.1, 33.0]; (3) relative HL long, 18.97-22.92\% SVL [19\%]; (4) relative SNL 55.24-65.55\% HL [64\%]; (5) Finger III scansors 12-15 [13]; (6) Toe IV scansors 13-18 [17]; (7) paravertebrals 221244 [240, 246]; (8) Ventral scales 123-132 [135, 141]; (9) supralabials $17-20$ [20, 21]; (10) infralabials 15-20 [17, 19]; (11) circumorbitals 40-50 [50, 54]; and (12) enlarged pore series (males) 12-17 [15] (Table 2).

Coloration in life: Dorsal ground color of head, trunk, and tail, light brownish tan to gray with a streak to a blotch pattern of greenish coloration on the lateral side. Some individuals have dense small rounded/banded dark brown speckles continuing down to the base of the tail while others have none; uniform color pattern in different sides of the body was documented; ventral perspective coloration apparent, light brown to gray ground color in contrast with the background coloration pattern; pronounced yellow coloration encircling the orbits. In general, most individuals lacking any discernable pattern. The first photograph of the species in life is provided in Figs. 5A, B, C.1, C.2.

Partial redescription: The following partial redescription of Pseudogekko isapa is based on type material and 13 referred specimens. Measurement data scored from the holotype are provided below in brackets. Body moderately large, elongate, slender, SVL 52.0-65.8 mm (females), 54.7-66.0 mm (males) $[62.1,63.4]$, limbs well developed; margins of the body smooth, dermal folds absent.

Head size moderate, distinctively differentiated from neck, and consistently characterized by only slightly hypertrophied temporal and adductor musculature (Siler et al. 2016); at dorsal and lateral aspect, snout is broadly and sharply rounded; HW 95.05-138.10\% MBW [118.8\%], 66.91-80.70\% HL [85.6\%]; HL $18.97-20.76 \%$ SVL [19.0\%]; SNL 79.27-96.70\% HW, $55.24-65.55 \%$ HL [63.6\%]; dorsal surfaces of the head relatively homogenous, with only moderately pronounced concave post nasal, internasal, prefrontal, and interorbital concavities; ED 26.92-38.10\% HL [33.05], 52.24-66.67\% END [66.10\%]; auricular opening small; tympanum deeply sunken; orbit large; eye large, pupil vertical, margin wavy; limbs and digits relatively short and moderately slender; thighs moderately thicker compared to brachium; TibL 12.37-15.72\% SVL [8.2\%], 68.29-97.56\% FL ; AGD 49.58-62.34\% SVL [50.6\%]. Tail short, only three referred specimens have intact tail, TL 39.67-84.04\% SVL [autotomized from posterior to cloaca]; round, not heavily depressed; TD $60.0-96.15 \%$ TW.

\section{Phylogenetic relationships and genetic divergence}

Following recent taxonomic revisions of the Brachymeles bonitae Complex and the Pseudogekko compresicorpus Complex (Siler et al. 2011a, Siler et al. 2014a), these new lineages from the RIG were diagnosed on the basis of a suite of unique morphological characters from all other members of their respective species complexes. In this study, we provided the first estimates of phylogenetic relationships for these RIG-endemic species (Fig. 6), confirmed their membership in the Brachymeles bonitae, and Pseudogekko compresicorpus complexes, respectively, and refined the diagnoses from each's most closely -related congeners.

Brachymeles dalawangdaliri: The complete, aligned matrix contains 41 samples of which 35 are Brachymeles, representing 16 of the 42 recognized taxa for the mitochondrial ND2 gene. Six additional samples were included as outgroups, consisting of representatives from the subfamilies Lygosominae and Scincinae within the family Scincidae and a single representative from the family Lacertidae. The phylogeny was rooted using samples of the lacertid Tachydromus sexlineatus.

The phylogenetic analyses of our ND2 dataset result in topologies largely consistent with previous studies (Siler et al. 2011a), and uniquely estimate the phylogenetic position of Brachymeles dalawangdaliri relative to its most closely-related 

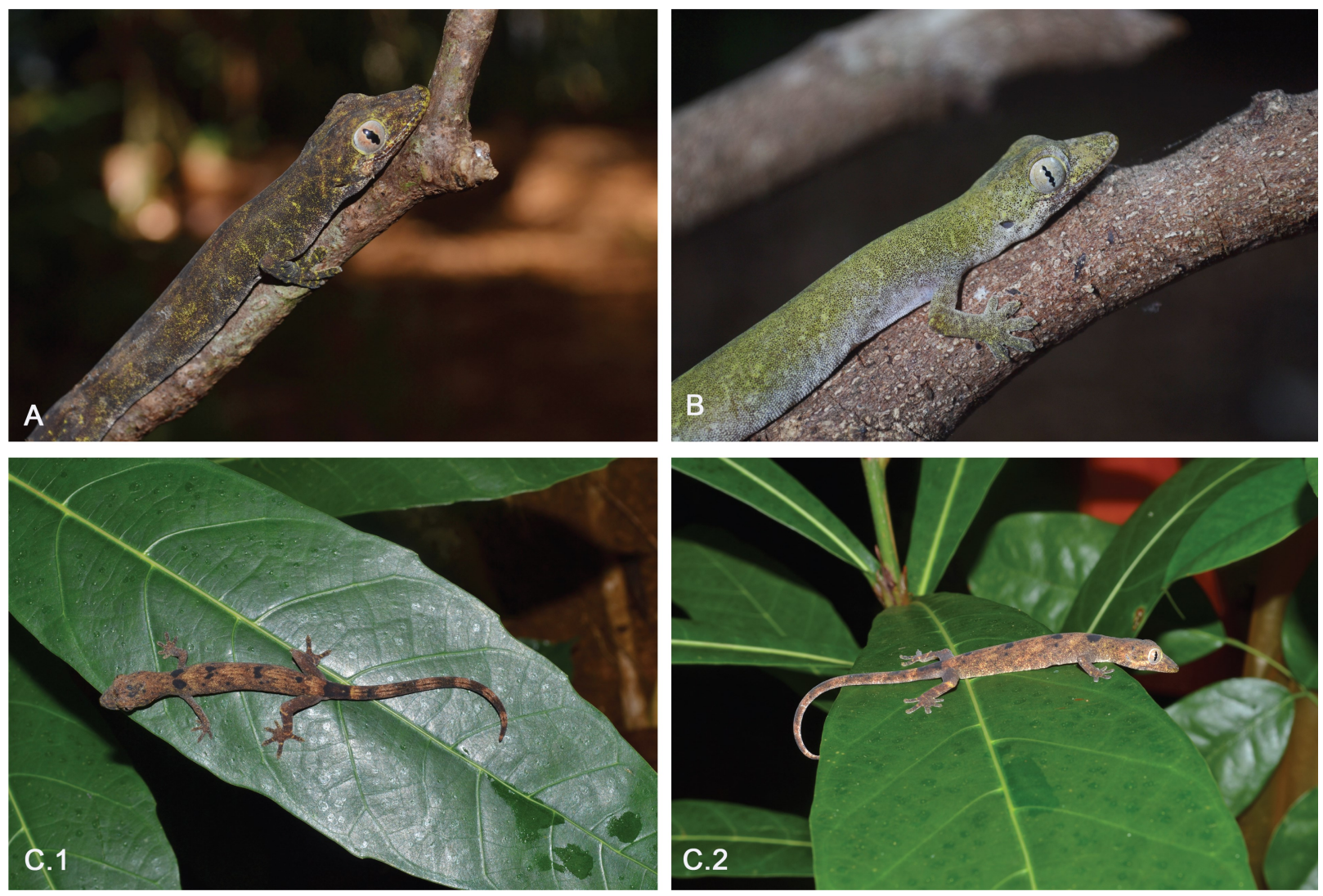

Figure 5. Photographs in life of Pseudogekko isapa. Adults: (A) UPLB-MNH-Z-NS 4615, (B) UPLB-MNH-Z-NS 4617, Juvenile: (C, D) UPLB-MNH-Z-NS 4613. Photos by CGM.

species. As in the Siler et al. (2011a) phylogenetic analysis, which was based on ND2 and five nuclear loci, our reanalysis based solely on ND2 data support the monophyly of the Brachymeles bonitae Complex, in which B. dalawangdaliri was recovered, with strong support. However, in our ND2-based reanalysis, species relationships within the Brachymeles bonitae Complex are partially unresolved (Fig. 6). However, if the relationships in our tree are correct $B$. dalawangdaliri appears to be most closely related to a clade consisting of Brachymeles burksi from the Mindoro PAIC and other Brachymeles bonitae Complex lineages from and adjacent to the Luzon PAIC (i.e. the Zambales Mountains of Luzon Island, and additional lineages from Polillo, Lubang, and Cagayan islands; Fig. 6; see also Siler et al. 2011a). Finally, although our ND2-based analyses do not resolve the phylogenetic position of $B$. dalawangdaliri with sufficient support to allow inferences of its historical biogeography, our novel genetic data, combined with additional support for non-overlapping morphological character states provide an improved understanding of $B$. dalawangdaliri as a distinct species endemic to the RIG, and confirms it is a member of the Brachymeles bonitae Complex.
Pseudogekko isapa: The complete, aligned matrix contains 46 samples of Pseudogekko, representing nine recognized taxa. Six additional samples were included from the family Gekkonidae, including representative taxa of the following genera: Cyrtodactylus, Gehyra, and Luperosaurus. Following initial unrooted analyses and other recent gekkonid phylogenetic studies (Siler et al. 2014a), our analysis was rooted using samples from the genus Cyrtodactylus.

Our phylogenetic analyses of the ND2 dataset resulted in a well-resolved topology for members of the genus Pseudogekko (Fig. 6). As has been observed in previous studies (Siler et al. 2014a), our analyses revealed two major clades: (1) Pseudogekko brevipes Complex (Pseudogekko brevipes, $P$. sumiklab, and P. atiorum), and (2) Pseudogekko compresicorpus Complex (Pseudogekko compresicorpus, P. ditoy, P. chavacano, $P$. smaragdinus, P. pungkaypinit, and P. isapa; Fig. 6). Pseudogekko isapa was recovered nested within the Pseudogekko compresicorpus Complex, sister to a clade of Pseudogekko compresicorpus populations sampled from the Luzon PAIC (Fig. 6). 
Table 2. Summary of representative meristic and mensural characters among adult specimens from the newly expanded, vouchered collections of Pseudogekko isapa. Mensural characters are given in $\mathrm{mm}$ as a range followed by mean \pm standard deviation in parentheses where sample size allows and are given as individual values otherwise. In cases of scale count variation within species, numbers of individuals showing specific counts are given in parentheses.

isapa $^{1}$

Siler et al. (2016) isapa

Sibuyan Island (newly collected series)

\begin{tabular}{|c|c|c|}
\hline Sample size (female, male) & 1,1 & 8,5 \\
\hline Snout-vent length (female) & 62.1 & $\begin{array}{c}52.0-65.8 \\
(61.5 \pm 5.5)\end{array}$ \\
\hline Snout-vent length (male) & 63.4 & $\begin{array}{c}54.7-66.0 \\
(61.2 \pm 4.2)\end{array}$ \\
\hline Axilla-groin distance & $32.1,33.0$ & $\begin{array}{c}27.1-37.4 \\
(33.0 \pm 3.8)\end{array}$ \\
\hline Total length & - & $\begin{array}{c}75.7-95.7 \\
(85.7 \pm 14.1)\end{array}$ \\
\hline Midbody width & $8.5,9.9$ & $\begin{array}{c}6.2-10.1 \\
(8.4 \pm 1.4)\end{array}$ \\
\hline Head length & $11.8,11.7$ & $\begin{array}{c}10.5-13.6 \\
(12.3 \pm 1.2)\end{array}$ \\
\hline Head length/snout-vent length & 19,19 & $\begin{array}{c}19-21 \\
(20 \pm 1)\end{array}$ \\
\hline Head width & $10.1,7.4$ & $\begin{array}{c}7.8-10.3 \\
(9.1 \pm 0.8)\end{array}$ \\
\hline Head width/snout-vent length & 16,15 & $\begin{array}{c}14-16 \\
(15 \pm 1)\end{array}$ \\
\hline Snout length & $7.5,7.2$ & $\begin{array}{c}6.4-8.8 \\
(7.8 \pm 0.9)\end{array}$ \\
\hline Snout length/head length & 64,62 & $\begin{array}{c}60-66 \\
(63 \pm 2)\end{array}$ \\
\hline Finger III scansor count & 13 & $12-16$ \\
\hline Toe IV scansor count & 17 & $13-18$ \\
\hline Supralabial count & 20,21 & $17-20$ \\
\hline Infralabial count & 17,19 & $15-20$ \\
\hline Circumorbital count & 50,54 & $40-50$ \\
\hline Paravertebral scale count & 240,246 & $221-246$ \\
\hline Ventral scale count & 135,141 & $123-132$ \\
\hline Enlarged pore series count (males) & 15 & $12-17$ \\
\hline
\end{tabular}

—, Total length not available; specimens lacking intact, original tail.

${ }^{1}$ Two specimens were available at the time of description, values for adult male holotype precede those for adult female paratype. 


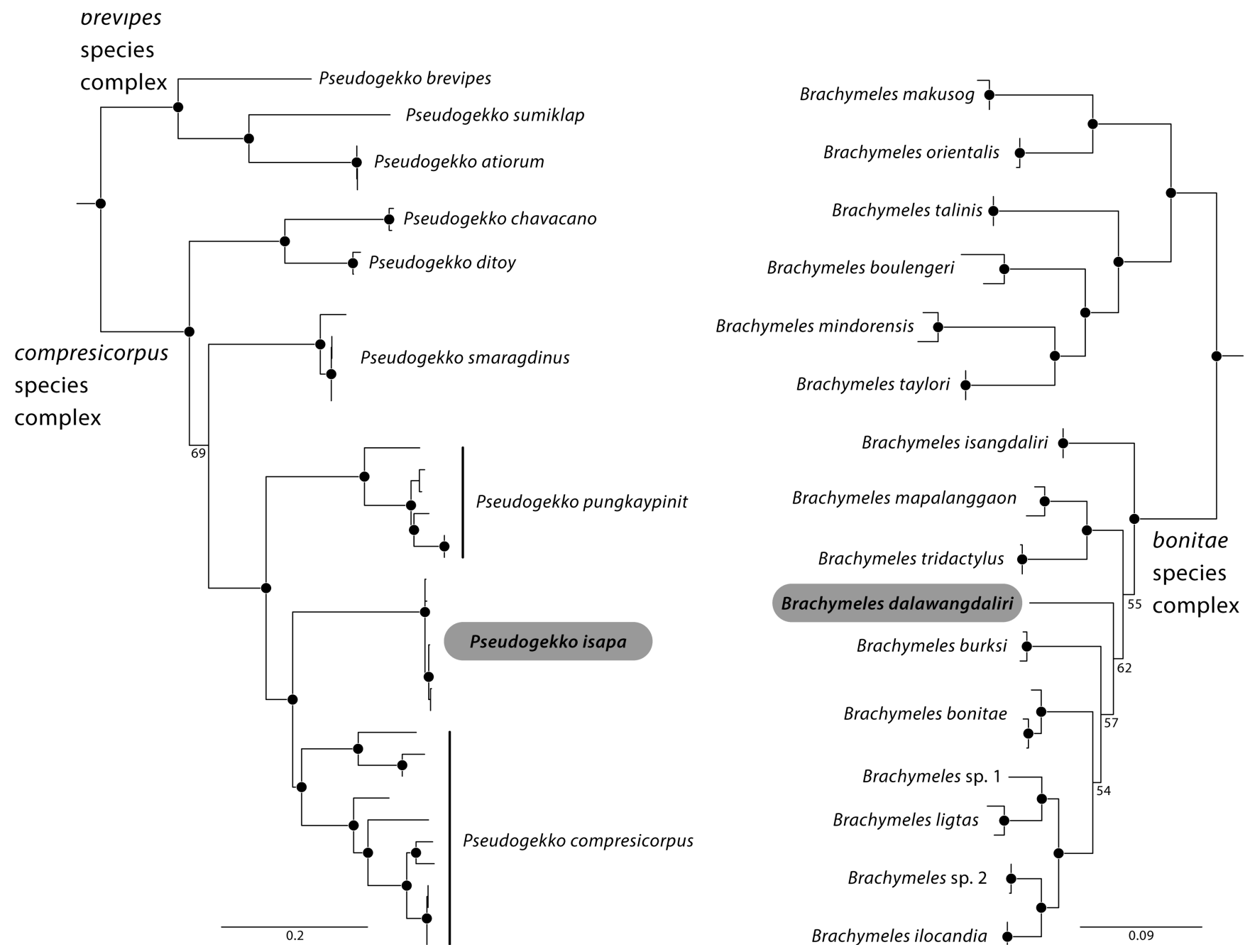

Figure 6. Preferred Maximum Likelihood topology from phylogenetic analyses of ND2 data for Pseudogekko (left) and Brachymeles (right; both topologies trimmed for simplicity to emphasize each focal group). Black circles indicate nodes with ultrafast bootstrap values above 95\%. Position of Pseudogekko isapa and Brachymeles dalawangdaliri highlighted with taxonomic labels in gray. Species complexes discussed in the manuscript are labeled for reference.

\section{Natural history observations}

Brachymeles dalawangdaliri: It took more than four decades between its initial discovery and when Siler et al. (2012b) redocumented Brachymeles cf. bonitae within rotting logs and in loose forest soil from Sibuyan Island. Davis et al. (2016) described this population as a new species, Brachymeles dalawangdaliri. As noted, based on Alcala's 1972 collection, this species was observed only from the last vestiges of primary forest on Tablas Island. As has been observed with most members of the Brachymeles bonitae Complex, $B$. dalawangdaliri specimens were observed in cooler, forested microhabitats, and appear to be patchily distributed, with few individuals documented in any single locality.

During the recent field surveys done in OctoberNovember, 2016 and May-June, 2017 in Mt. Guiting-Guiting
Natural Park, four additional female and three additional male specimens of $B$. dalawangdaliri were collected in pitfall traps under large boulders of ultramafic rocks and rotting logs in mature secondary forests of Mt. Guiting-Guiting Natural Park (213-929 masl). Specimens were well camouflaged in loose forest soil under rotting logs and ultramafic rocks. This species is known to be sympatric with Brachymeles talinis on the islands of Tablas and Sibuyan (Siler and Brown 2010, Davis et al. 2016). Although this species does appear to be a forest obligate, little information is known on the ecology and distribution of $B$. dalawangdaliri, which is at least partially the result of its secretive and semi-fossorial lifestyle.

Pseudogekko isapa: This enigmatic species is known from the islands of Tablas and Sibuyan (Siler et al. 2016). It is 
believed that the species may eventually be discovered on other smaller islands in the RIG. Like most members of this genus, few individuals have been collected relative to members of other genera of gekkonid lizards (Davis et al. 2016). More than four decades passed since the collections of the first specimens, and Siler et al. (2012b) redocumentation of this species. Prior to our recent surveys, this species was represented in museum collections globally by only two individuals - one adult female (CAS 139713) and one adult male (PNM 9816). We assume the low numbers of specimens in biodiversity repositories is a testament to its secretive behavior (Siler et al. 2016, Davis et al. 2015), which likely has resulted in a paucity of information about its ecology and natural history.

Pseudogekko isapa was discovered to be phenotypically allied with the Pseudogekko compresicorpus Complex (Siler et al. 2016, Brown and Alcala 1978). Like other members of this genus, $P$. isapa appears to be an obligate primary forest species. Recently, we documented a number of new observations of the species from Mt. Guiting-Guiting Natural Park (elevational range of 50-742 masl). All specimens were collected between 21:30-23:00H in October-November 2016 and May-June, 2017, on small vines and shrubs 5-10 $\mathrm{m}$ above the ground, along trails or near riparian areas, in secondary-growth forest. Interestingly, most vouchered specimens have autotomized tails (including the holotype), suggesting elevated predation pressures or elevated levels of intraspecific agonism.

\section{Discussion}

\section{Phylogenetic affinities}

Historically, the shared body plans and similar external morphological features among populations of the Brachymeles bonitae and Pseudogekko compresicorpus Complexes, and the lack of even the most limited statistical population sampling across the Philippines, have restricted more thorough evaluations of cryptic species diversity across the archipelago. The combination of our molecular phylogenetic analysis and comparisons of morphological characteristics from the historically known and recently collected specimens of both RIG endemic species further support their recognition as unique, endemic species.

The distribution of these unique species on Tablas and Sibuyan islands, both restricted to the RIG, is not surprising given the number of amphibian and reptile species endemic to this small island group. Our phylogenetic analyses support Brachymeles dalawangdaliri as a divergent lineage within the Brachymeles bonitae Complex, as hypothesized by Davis et al. (2016). This study, including new sequence data from $B$. dalawangdaliri (a taxon never before included in a phylogenetic analysis due to the absence of available genetic material) has allowed phylogenetic assignment of this endemic RIG species to the Brachymeles bonitae Complex; however, without strong support for species level relationships within this clade, we are unable to infer its historical biogeographical origins. Although the species appears to be closely related to the clade consisting of Brachymeles bonitae, B. ligtas, B. ilocandia, and two other undescribed lineages (Fig. 6), our inference of the historical biogeography of the group must await future studies, perhaps employing the six loci from Siler et al. (2011a) or other markers.

In comparison, past studies on the genus Pseudogekko recognized Pseudogekko isapa as a unique species based on single records from Tablas and Sibuyan islands, and hypothesized that this lineage was a member of the Pseudogekko compresicorpus Complex based on distinct morphological characters (e.g. infralabials 17, enlarged scales in the precloacals region 15 , circumorbitals 54 ). The results of our phylogenetic analyses confirm $P$. isapa is appropriately regarded as a member of this complex (which also includes $P$. pungkaypinit) and is most closely-related to $P$. compresicorpus (Fig. 6).

\section{Implications for the biogeography of Sibuyan}

It has been long recognized that the extent of connections among modern islands undergoing sea-level oscillations during the Pleistocene influenced the assembly of biodiversity in the Philippines (see Brown and Diesmos, 2009). Sibuyan Island, separated by deep-water channels from Romblon and Tablas islands, and the neighboring landmasses of the surrounding PAICs, harbors high levels of endemism and distinct biological communities (Goodman and Ingle 1993, Goodman et al. 1995, Siler et al. 2012b). Phylogenetic analyses from this study contribute to our understanding of species diversity in the RIG, and the entirely Philippine-endemic radiations of the genera Brachymeles and Pseudogekko represent remarkable systems to further understand processes of vertebrate diversification, morphological evolution, and the unique biogeographic history of small island groups throughout the archipelago (Brown et al. 2013).

From the few published phylogenetic studies on island endemics of the RIG, several biogeographic patterns of colonization involving Sibuyan Island can be ascertained. For example, in recent phylogenetic studies, the RIG endemic geckos (Gekko romblon and G. coi) were recovered as sister lineages to endemic species of the Luzon and West Visayan PAICs (Siler et al. 2012c) and their non-simultaneous divergence times with other small island endemics suggest dispersal and colonization as an explanation for their presence on Sibuyan (as opposed to lineages produced by overland range expansion and subsequent sea-level vicariance; Oaks et al. 
2019). The widespread species Cyrtodactylus philippinicus was weakly supported as related to populations from the Mindoro and Luzon PAICs (Siler et al. 2010a). Varanus nuchalis from Sibuyan Island was recovered to be most closely related to $V$. nuchalis from Masbate Island of the West Visayan PAIC (Welton et al. 2014). Based on a recent multilocus phylogeny of the frog family Ceratobatrachidae, the RIG endemic species, Platymantis lawtoni showed notable phylogenetic affinities with the subgenus Tirahanulap, a morphologically and ecologically cohesive group that corresponds to the Platymantis hazelae group of Luzon Island and the West Visayan PAIC. Platymantis levigatus, (from Tablas and Sibuyan islands; subgenus Lahatnanguri; Brown et al. 2015) was recovered closely related to Platymantis species from Luzon Island, West Visayan lineages, and undescribed species from the Mindanao PAIC. Finally, flying lizards of the RIG include two species (Draco spilopterus and D. quadrasi), with affinities to Luzon and Mindoro islands, respectively (McGuire and Kiew 2001, Siler et al. 2012c). Previous studies by Brown and Alcala (1970), Goodman et al. (1995), Brown et al. (2011), and Siler et al. (2012b) suggest that the remarkable herpetological species assemblages of Sibuyan Island assembled most likely due to cross-water dispersal followed by isolation and divergence, possibly via rafting associated with river-discharged mats of vegetation, topsoil, logs, forest debris, etc. (Brown 2016).

\section{Phenotypic variation}

Our results shed light on the systematics of the two RIG endemic species and, not surprisingly, suggest a wider range of phenotypic variation within both focal species. Our observations of morphological variation for the most part matched reports of the type material from the original species' descriptions, providing additional support for the recognition of these two distinct, endemic Sibuyan Island lineages. Additionally, we reported here on newly-characterized phenotypic variation and provided the first descriptions of live coloration based on increased numbers of samples of specimens from both species (Figs. 4A, B.1, B.2; 5A, B, C.1, C.2). In summary, each species possesses unique diagnostic morphological characters, which correspond to Sibuyan Island lineages identified in phylogenetic analyses we presented here for the first time.

\section{Conservation implications}

The RIG of the central Philippines is known for a relatively impressive (given the small land area) number of endemic amphibian and reptiles species, which are distinct from those on nearby PAICs (e.g. Platymantis levigatus, P. lawtoni, Gekko romblon, G. coi, Pseudogekko isapa, Brachymeles dalawangdaliri). This small island group should be considered as a fragile faunal subregion in need of increased protection and conservation (Goodman and Ingle 1993, Goodman et al. 1995, Siler et al. 2012b). It is important that continued efforts be made to conduct surveys focused throughout the ranges of the RIG's endemic species to continue our assessments of appropriate conservation status and long-term conservation actions. Such continued research on these focal RIG-endemic species, will lead to a greater understanding of diversification patterns and species' boundaries and biogeography of the central Philippines (Esselstyn and Goodman 2010, Siler et al. 2011a, Brown et al. 2013). However, despite improved sampling now available for $P$. isapa and $B$. dalawangdaliri, we still do not find that either species qualifies for formal threatened status under IUCN criteria (IUCN 2019), given the fact that both species ranges are encompassed by a major protected area. We still lack pertinent data that might reveal potential population declines, and we lack information on the ecology, natural history, and intraspecific phenotypic diversity of both species. Therefore, we strongly recommend that immediate, exhaustive survey efforts be undertaken to study the status of wild populations of both species on Sibuyan Island, and throughout the RIG.

\section{Acknowledgments}

We are particular grateful to Dr. Angel C. Alcala for his pioneering work documenting the diversity and taxonomic distinctive of amphibians and reptiles of Sibuyan, Tablas, and Romblon islands (1971-1978) and for his support of our efforts to revisit and resurvey central Philippine centers of herpetological endemism. We thank the Biodiversity Management Bureau (BMB) of the Philippine Department of Environment and Natural Resources (DENR) for facilitating collecting and export permits necessary for this and related studies; we are particularly grateful to T. Lim, C. Custodio, A. Tagtag, and J. De Leon for their logistical support of this research. We thank the DENR Region IV-B for facilitating collecting permits necessary for this study. We are particularly grateful to CESE N.Y. Bernardino, Protected Area Management Board of Mt. Guiting-Guiting Natural Park, and PASu M.R. Rocero. We are also thankful for the constant field advices and support of Dr. Aimee Lynn B. Dupo and Prof. Phillip Alviola. Fieldwork was conducted under the Memorandum of Understanding with the University of Kansas, UPLB, and UPLB Museum of Natural History, Wildlife Gratuitous Permit to Collect No. MIMAROPA-2017-0005, and the University of Kansas (KU) Institutional Animal Care and Use Committees (IACUC) approval (158-04). Perry L. Wood's contributions to this paper constitute publication number 925 of the Auburn 
University Museum of Natural History. Financial support for fieldwork was provided by the Rufford Small Grant and DOSTASTHRDP, molecular data collection and earlier fieldwork supported by U.S. National Science Foundation grants to RMB (DEB 0743491, 1654388) at the University of Kansas, and assistance from the University of the Philippines Los Baños Museum of Natural History (UPLB-MNH), travel funds from the Office of the International Linkages University of the Philippines System, and equipment support for fieldwork from IdeaWild to CGM.

\section{Literature Cited}

Aurelio, M.A., R.E. Peña \& K.J.L. Taguibao, 2013. Sculpting the Philippine archipelago since the Cretaceous through rifting, oceanic spreading, subduction, obduction, collision and strike-slip faulting: Contribution to IGMA5000. Journal of Southeast Asian Earth and Sciences, 72: 102107.

Brown, R.M. 2016. Biogeography of Land Vertebrates. 2016. In: Kliman, R.M. (ed.), The Encyclopedia of Evolutionary Biology. Academic Press/Elsevier Inc., Oxford. pp. 211220.

Brown, R.M. \& A.C. Diesmos, 2009. Philippines, Biology. In: Gillespie, R. \& D. Clague, (ed.), Encyclopedia of Islands. University of California Press, Berkeley, California, USA. pp. 723-732.

Brown, R.M., C.D. Siler, C.H. Oliveros, A.C. Diesmos, \& A C. Alcala. 2011. A new Gekko from Sibuyan Island, central Philippines. Herpetologica, 67: 460-476.

Brown, R.M., C.D. Siler, C.H. Oliveros, J.A. Esselstyn, A.C. Diesmos, P.A. Hosner, C.W. Linkem, A.J. Barley, J.R. Oaks, M.B. Sanguila, L.J. Welton, R.G. Moyle, A.T. Peterson \& A.C. Alcala, 2013. Evolutionary processes of diversification in a model island archipelago. Annual Review of Ecology, Evolution, and Systematics, 44: 411435.

Brown, R.M., C.D. Siler, S. Richards, A.C. Diesmos \& D.C. Cannatella. 2015. Multilocus phylogeny and a new classification for Southeast Asian and Melanesian forest frogs (family Ceratobatrachidae). Zoological Journal of the Linnaean Society, 174: 130-168.

Brown, W.C., 1956. A revision of the genus Brachymeles (Scincidae), with descriptions of new species and subspecies. Breviora, 54: 1-19.

Brown, W.C. \& A.C. Alcala, 1970. The zoogeography of the herpetofauna of the Philippine Islands, a fringing archipelago. Proceedings of the California Academy of Sciences, Fourth Series, 18: 105-130.

Brown, W.C. and A.C. Alcala. 1974. New frogs of the genus Platymantis (Ranidae) from the Philippines. Occasional Papers of the California Academy of Sciences 113: 1-12.

Brown, W.C., \& A.C. Alcala 1978. Philippine Lizards of the Family Gekkonidae. Silliman University Press, Dumaguete City. 146 pp.

Brown, W.C., \& A.C. Alcala, 1980. Philippine Lizards of the Family Scincidae. Silliman University Press, Dumaguete
City. 264 pp.

Brown, W.C., \& D.S. Rabor, 1967. Review of the genus Brachymeles (Scincidae), with descriptions of new species and subspecies. Proceedings of the California Academy of Sciences, Fourth Series, 15: 525-548.

Davis, D.R., K.D. Feller, R.M. Brown \& C.D. Siler, 2014. Evaluating the diversity of Philippine slender skinks of the Brachymeles bonitae Complex (Reptilia: Squamata: Scincidae): redescription of $B$. tridactylus and descriptions of two new species. Journal of Herpetology, 48: 480-494.

Davis, D.R., A.D. Geheber, J.L. Watters, M.L. Penrod, K.D. Feller, A. Ashford, J. Kouri, D. Nguyen, K. Shauberger, K. Sheatsley, C. Winfrey, R. Wong, M.B. Sanguila, R.M. Brown \& C.D. Siler, 2016. Additions to Philippine slender skinks of the Brachymeles bonitae complex (Reptilia: Squamata: Scincidae) III: a new species from Tablas Island. Zootaxa, 4132: 30-43.

Davis, D.R., J.L. Watters, G. Köhler, C. Whitsett, N.A. Huron, R.M. Brown, A.C. Diesmos \& C.D. Siler, 2015. Redescription of the rare Philippine false gecko Pseudogekko brevipes (Reptilia: Squamata: Gekkonidae) and description of a new species. Zootaxa, 4020(2): 357374.

Esselstyn, J.A. \& S.M. Goodman, 2010. New species of shrew (Soricidae: Crocidura) from Sibuyan Island, Philippines. Journal of Mammalogy, 91(6): 1467- 1472.

Geheber, A.D., D.R. Davis, J.L. Watters, M.L. Penrod, K.D. Feller, C.S. Davey, E.D. Ellsworth, R.L. Flanagan, B.D. Heitz, T. Moore, M.D.C. Nguyen, A. Roberts, J. Sutton, M.B. Sanguila, C.W. Linkem, R.M. Brown, \& C.D. Siler, 2016. Additions to Philippine slender skinks of the Brachymeles bonitae complex (Reptilia: Squamata: Scincidae) I: a new species from Lubang Island. Zootaxa, 4132: 1-14.

Goodman, S.M. \& N.R. Ingle. 1993. Sibuyan Island in the Philippines: threatened and in need of conservation. Oryx, 27: 174-180.

Goodman, S.M., D.E. Willard, \& P.C. Gonzales. 1995. The birds of Sibuyan Island, Romblon Province, Philippines, with particular reference to elevational distribution and biogeographic affinities. Fieldiana Zoology, new series 82: $1-57$.

Hall, R., 1998. The plate tectonics of Cenozoic SE Asia and the distribution of land and sea. In: Hall, R. \& Holloway, J.D. (ed.), Biogeography and Geological Evolution of SE Asia. Backhuys Publishers, Leiden. pp. 99-131.

Heaney, L.R. \& J.C. Regalado, Jr., 1998. Vanishing Treasures of the Philippine Rainforest. The Field Museum, Chicago. 96 pp. International Union for Conservation of Nature (IUCN), 2019. The IUCN Red List of Threatened Species. Version 2019-2. Available from: http:// www.iucnredlist.org/ (accessed 26 July 2019).

Kalyaanamoorthy, S., B.Q. Minh, T.K. Wong, A. von Haeseler \& L.S. Jermiin, 2017. ModelFinder: fast model selection for accurate phylogenetic estimates. Nature Methods, 14: 587.

Katoh, K. \& D.M. Standley, 2013. MAFFT multiple sequence alignment software version 7: improvements in performance and usability. Molecular Biology and Evolution, 30: 772-780.

Köhler, G., 2012. Color Catalog for Field Biologists. Herpeton, Offenbach, Germany. 49 pp. 
Nguyen, L.T., H.A. Schmidt, A. von Haeseler, \& B.Q. Minh, 2015. IQ-TREE: A fast and effective stochastic algorithm for estimating maximum likelihood phylogenies. Molecular Biology and Evolution, 32: 268-274.

Minh, B.Q., M.A.T., Nguyen \& A. von Haeseler, 2013. Ultrafast approximation for phylogenetic bootstrap. Molecular Biology and Evolution, 30: 1188-1195.

McGuire, J.A. \& Kiew, B.H. 2001. Phylogenetic systematics of Southeast Asian flying lizards (Iguania: Agamidae: Draco) as inferred from mitochondrial DNA sequence data. Biological Journal of the Linnean Society 72: 203229.

Oaks, J.R., C.D. Siler \& R.M. Brown. 2019. The comparative biogeography of Philippine geckos challenges predictions from a paradigm of climate-driven vicariant diversification across an island archipelago. Evolution 73: 1151-1167.

Sabaj, M.H., 2016. Standard symbolic codes for institutional resource collections in herpetology and ichthyology: an online reference. Version 6.5. American Society of Ichthyologists and Herpetologists, Washington, D.C., USA. Available from: http://www.asih.org/ (accessed 7 February 2019).

Siler, C.D., 2010. Squamata, Scincidae, Brachymeles elerae (Taylor, 1917): rediscovery in Old Balbalan, Cordillera Mountain Range, Luzon Island, Philippines, and natural history. Check List, 6: 616-618.

Siler, C.D., D.S. Balete, A.C. Diesmos \& R.M. Brown, 2010 b. A new legless loam-swimming lizard (Reptilia: Squamata: Scincidae: genus Brachymeles) from the Bicol Peninsula, Luzon Island, Philippines. Copeia, 2010: 114-122.

Siler, C.D. \& R.M. Brown, 2010. Phylogeny-based species delimitation in Philippine slender

skinks (Reptilia: Squamata: Scincidae: Brachymeles): taxonomic revision of pentadactyl

species groups and description of three new species. Herpetological Monographs, 24: 1-54.

Siler, C.D., A.C. Diesmos, A.C. Alcala \& R.M. Brown, 2011a. Phylogeny of Philippine slender skinks (Scincidae: Brachymeles) reveals underestimated species diversity, complex biogeographical relationships, and cryptic patterns of lineage diversification. Molecular Phylogenetics and Evolution, 59: 53-65.

Siler, C.D., A.C. Diesmos \& R.M. Brown, 2010a. A new loamswimming skink, genus Brachymeles (Reptilia: Squamata: Scincidae) from Luzon and Catanduanes Islands, Philippines. Journal of Herpetology, 44: 49-60.

Siler, C.D., R.I. Crombie, A.C. Diesmos \& R.M. Brown, 2011c. Redescriptions of two poorly known slender skinks, Brachymeles bicolor and Brachymeles pathfinderi (Reptila: Squamata: Scincidae), from the Philippines. Journal of Herpetology, 45: 355-369.

Siler, C. D., D.R. Davis, A.C. Diesmos, F. Guinto, C. Whitsett \& R.M. Brown, 2016. A new species of Pseudogekko (Squamata: Gekkonidae) from the Romblon Island Group, Central Philippines. Zootaxa, 4139(2): 248-260.

Siler, C. D., T.A. Dececchi, C.L. Merkord, D.R. Davis, T.J. Christiani \& R.M. Brown, 2014b. Cryptic diversity and population genetic structure in the rare, endemic, forestobligate, slender geckos of the Philippines. Molecular Phylogenetics and Evolution, 70: 204-209.

Siler, C.D., A.M. Fuiten, R.M. Jones, A.C. Alcala \& R.M.
Brown, 2011b. Phylogeny-based species delimitation in Philippine slender skinks (Reptilia: Squamata: Scincidae) II: taxonomic revision of Brachymeles samarensis and description of five new species. Herpetological Monographs, 25: 76-112.

Siler, C.D., R.M. Jones, A.C. Diesmos, M.L. Diesmos \& R.M. Brown, 2012a. Phylogeny-based species delimitation in Philippine slender skinks (Reptilia: Squamata: Scincidae) III: taxonomic revision of the Brachymeles gracilis Complex, with descriptions of three new species. Herpetological Monographs, 26: 135-172.

Siler, C.D., R.M. Jones, L.J. Welton \& R.M. Brown, 2011d. Redescription of tetradactyl Philippine

slender skinks (genus Brachymeles). Herpetologica, 67: 300-317.

Siler, C.D., J.R. Oaks, L.J. Welton, C.W. Linkem, J.C. Swab, A.C. Diesmos \& R.M. Brown, 2012c. Did geckos ride the Palawan raft to the Philippines? Journal of Biogeography, 39:1217-34.

Siler, C.D., E.L. Rico, M.R. Duya \& R.M. Brown, 2009. A new limb-reduced, loam-swimming skink (Squamata: Scincidae: Brachymeles) from central Luzon Island, Philippines. Herpetologica, 65: 449-459.

Siler, C.D., J.C. Swab, C.H. Oliveros, A.C. Diesmos, L. Averia, A.C. Alcala \& R.M. Brown, 2012b. Amphibians and reptiles, Romblon Island Group, central Philippines: comprehensive herpetofaunal inventory. Check List, 8(3), 443-462.

Siler, C.D., L.J. Welton, D.R. Davis, J.L. Watters, C.S. Davey, A.C. Diesmos, M.L. Diesmos \& R.M. Brown. 2014 a. Taxonomic revision of the Pseudogekko compresicorpus Complex (Reptilia: Squamata: Gekkonidae), with descriptions of three new species. Herpetological Monographs, 28: 110-139.

Steppan, S.J., C. Zawadzki, \& L.R. Heaney, 2003. Molecular phylogeny of the endemic Philippine rodent Apomys (Muridae) and the dynamics of diversification in an oceanic archipelago. Biological Journal of the Linnean Society, 80 (4): 699-715.

Taylor, E.H., 1917. Brachymeles, a genus of Philippine lizards. Philippine Journal of Science, 12: 267-279.

Trifinopoulos, J., L.T. Nguyen, A. von Haeseler, \& B.Q. Minh, 2016. W-IQ-TREE: a fast online phylogenetic tool for maximum likelihood analysis. Nucleic Acids Research, 44 (W1): W232-W235.

Wagner, P., W. Böhme, O.S. Pauwels \& A. Schmitz, 2009. A review of the African red-flanked skinks of the Lygosoma fernandi (Burton, 1836) species group (Squamata: Scincidae) and the role of climate change in their speciation. Zootaxa, 2050, 1-30.

Welton, L. J., P.L. Wood, Jr., J.R. Oaks, C.D. Siler \& R.M. Brown. 2014. Fossil-calibrated phylogeny and historical biogeography of Southeast Asian water monitors (Varanus salvator Complex). Molecular Phylogenetic Evolution, 94: 537-547.

Yumul Jr., G.P., C.B. Dimalanta, K.L. Queaño \& E.J. Marquez, 2009a. Philippines, geology. In: R.G. Gillespie and D.A. Clague, (ed.), Encyclopedia of Islands. University of California Press, Berkeley, CA. pp. 732-738

Yumul Jr., G.P., C.B. Dimalanta, E.J. Marquez \& K.L. Queaño, 2009b. Onland signatures of the Palawan microcontinental 
block and Philippine mobile belt collision and crustal growth process: a review. Journal of Asian Earth Sciences, 34: 610-623. 
APPENDIX I. Additional specimens examined for members of the genus Brachymeles. Numbers in parentheses indicate the number of specimens examined. Several sample sizes are greater than those observed in the description due to the examination of subadult specimens which were excluded from morphometric analyses. All species examined are from the Philippines except Brachymeles apus and B. miriamae. Museum abbreviations for specimens examined follow those from Sabaj (2016).

Brachymeles apus (1). BORNEO: Malaysia: Sabah: (SP 06915).

Brachymeles bicolandia (20). LUZON ISLAND: ALBAY Province: Municipality of Malinao: Paratypes (CAS 140065, 152025, 152026); Municipality of Tabaco City: Holotype (PNM 9756), Paratopotypes (KU 324005324011, 324015, 324016, 323087, PNM 9757-9760); CAMARINES SUR PROVINCE: Municipality of Pili: Paratypes (CAS-SU 24173, 24413).

Brachymeles bicolor (24). LUZON ISLAND: AURORA Province: Municipality of Maria Aurora: (KU 323149323152); Cagayan Province: Municipality of Baggao: (CAS 186111, USNM 140847, 498829, 498830, 498833); Isabela Province: (KU 324097-324099, PNM 5785, 9568 -9577); Kalinga Province: (FMNH 259438).

Brachymeles boholensis (39). BOHOL ISLAND: BоHOL Province: Municipality of Sierra Bullones: Holotype (CAS -SU 24528), Paratypes (CAS-SU 24502-24504, 24518, 24520-24525, 24541, 24543), (CAS-SU 18709, 18717, 24867, 25443, 25444, 25447, KU 323944, 323948, 323949, 323952-323956, 323960, 323962, 323963， 323966, $323970,323972,323975,323976,323981,323982$, 323990, 324001).

Brachymeles bonitae (7). LUZON ISLAND: LAGUNA Province: Municipality of Los Baños: Paratype (MCZ 26585), (CAS 62578); Quezon Province: Municipality of Tayabas: (KU 326089); POLILLO ISLAND: QuEzoN Province: Municipality of Polillo: (CAS 62278, 62279, 62575, KU 307747).

Brachymeles brevidactylus (3). LUZON ISLAND: SORSOGON Province: Municipality of Irosin: Holotype (PNM 9764), Paratypes (PNM 4856, TNHC 62469).

Brachymeles burksi (26). MARINDUQUE ISLAND: MarinduQUe Province: Municipality of Buenavista: (KU 320417, 320418); MINDORO ISLAND: MINDORO Oriental Province: (CAS-SU 25782); Municipality of Baco: (CAS-SU 25712, 25713, 25724, 25792, 25793, 25880, 25886-25889, 25891, 25893-25896, 25899, 25903, 25904); Municipality of Bansud: Holotype (MCZ 112202), (CAS 62064), (MCZ 20130); Municipality of Gloria: (KU 307749); Municipality of Magsaysay: (KU 307748).

Brachymeles cebuensis (8). CEBU ISLAND: CeBU Province: Municipality of Carcar: Holotype (CAS-SU 24400),
Paratypes (CAS 102405, CAS-SU 24396, 24397, 24399, 24401, 24403); Municipality of Cebu City: Paratype (CASSU 27537).

Brachymeles cobos (10). CATANDUANES ISLAND: Catanduanes Province: Municipality of Virac: Holotype (PNM 9761), Paratopotypes (KU 306311, 308077, 324019324021, 324025, 324026, PNM 9762, 9763).

Brachymeles dalawangdaliri (14). SIBUYAN ISLAND: Romblon Province: Municipality of Magdiwang: (UPLBMNH-Z-NS 4848-4854); TABLAS ISLAND: RoMBLON Province: Municipality of San Agustin: Holotype (CAS 137149), Paratypes (CAS 137148, 137150-137154).

Brachymeles elerae (5). LUZON ISLAND: KALINGA Province: Municipality of Balbalan: (CAS 61499, 61500, PNM 9563, 9564), Paratype (CM 1717).

Brachymeles gracilis (69). MINDANAO ISLAND: DAVAO DEL Sur Province: (FMNH 52642-52644, 52646, 52647, 52662, 52669, 52670); Municipality of Davao City: (CAS 124803, 124804, 139293-139295, 139301-139305); Municipality of Digos City: (CAS 124806-124808, 139296139300); Municipality of Kiblawan: (KU 326096, 326098326108, 326298, 326299); Municipality of Malalag: (CASSU 24158-24165, 24171, CAS 124809-124812, 139306139311); Municipality of Toril: (CMC 12170, 12171); South Cotabato Province: (MCZ 26539, 26541, 26543, 26544, 26546, 26548-26550).

Brachymeles hilong (28). MINDANAO ISLAND: AGUSAN DEL Norte Province: Municipality of Cabadbaran: Holotype (CAS-SU 24407), Paratypes (CAS-SU 102406, 133578, CAS-SU 24411, 133577, 133579, 133581, 133582, 133609, 133612, 133692, 133693, 133703-133706, 133743, 133745 -133747); Agusan del Sur Province: Municipality of San Francisco: (KU 319934-319940); SuRIGAO DEL SUR Province: Municipality of Lanuza: Paratype (CAS-SU 24315).

Brachymeles ilocandia (9). CAMIGUIN NORTE ISLAND: Cagayan Province: Municipality of Calayan: Holotype (PNM 9819), Paratopotypes (KU 307967, 308019, 308020, 308027, 308030), Paratype (KU 304567); LUZON ISLAND: Kalinga Province: Paratype (FMNH 259449); LUZON ISLAND: MountaIn Province: Paratype (CAS 61377).

Brachymeles isangdaliri (2). LUZON ISLAND: AURORA 
Province: Municipality of Baler: Holotype (PNM 9791), Paratopotype (KU 323085).

Brachymeles kadwa (141). CALAYAN ISLAND: CAGAYAN Province: Municipality of Calayan: Paratypes (KU 304875, 304897, 304900, 304902, 304903, 304905, $304906,304915,304929,304941,304908,304899$, 304907, 304909, 304921, 304941); CAMIGUIN NORTE ISLAND: Cagayan Province: Municipality of Calayan: Paratypes (KU 304559, 304575, 304593, 304708, 304754, 307984 , 307996, 307998, 308011, 304558, 304562$304565, \quad 304569, \quad 304571-304574, \quad 304627-304630$, 304643, 304647, 304696-304699, 304704-304707, 304709 -304712 , 304714, 304753, 304755-59, 307965, 307966, 307985 , 307986, 307997, 307999-308003, 308006308010, 308012-308015, 308017, 308018); LUZON ISLAND: AURORA Province: Municipality of Baler: Holotype (PNM 9721), Paratopotypes (KU 323092, 323094 -323096, 323100, 323104, 323106, 323090, 323093, 323097-323099, 323101-323103, 323105, 323107); Municipality of Casiguran: (KU 323108-48); Municipality of San Luis: (KU 322320).

Brachymeles libayani (45). LAPINIG CHICO ISLAND: BoHOL Province: Municipality of President Carlos P. Garcia: Paratypes (CAS-SU 27556, 28454, 28455); LAPINIG GRANDE ISLAND: Bohol Province: Municipality of President Carlos P. Garcia: Holotype (PNM 9749), Paratopotypes (KU 320428-320430, 320435-320463, 320467, PNM 9750-9755), Paratype (CAS-SU 28453); POLONG DAKO ISLAND: BoHol Province: Municipality of President Carlos P. Garcia: Paratype (CAS -SU 27554).

Brachymeles ligtas (5). LUBANG ISLAND: MINDORO Occidental Province: Municipality of Lubang: Holotype (PNM 9818), Paratopotypes (KU 320470, 320471, 320473), Paratype (KU 307755).

Brachymeles lukbani (14). LUZON ISLAND: CAMARINES Norte Province: Municipality of Labo: Holotype (PNM 9567), Paratopotypes (PNM 9589-9592, KU 313597313599, 313601, 313603, 313604, 313606, 313608, FMNH 270191).

Brachymeles makusog (17). CATANDUANES ISLAND: Catanduanes Province: Municipality of Gigmoto: Holotype (PNM 9565), Paratopotypes (PNM 9583, 9584, KU 308126, 308128, 308136, 308208); LUZON ISLAND: Camarines Norte Province: Municipality of Labo: Paratypes (KU 313612-313614, 313616, 313617, PNM 9585-9588, FMNH 270200).

Brachymeles mapalanggaon (8). MASBATE ISLAND: Masbate Province: Municipality of Masbate City:
Holotype (PNM 9792), Paratopotype (KU 323938); Municipality of Mobo, Paratypes (CAS 144223, 144236, 144237, 144239, 144270, 144340).

Brachymeles mindorensis (34). MINDORO ISLAND: MINDORO Occidental Province: Municipality of Paluan: (KU 304351-304355, 304412, 304413, 304488, 307739-307742, 308404, 308447, 308448, 308534); Mindoro ORIENTAL Province: Municipality of Naujan: Holotype (CAS-SU 24487), Paratypes (CAS-SU 24549-24554, 24561, 24562, 24564; 24566, 24568, 24570, 24573, 24574, 24577-24579).

Brachymeles minimus (6). CATANDUANES ISLAND: Catanduanes Province: Municipality of Gigmoto: (KU 308129-308131, 308210-308212).

Brachymeles miriamae (2). THAILAND: NAKHON RATCHASIMA Province: Wang Nam Khieo District: (KU 327692, 327693).

Brachymeles muntingkamay (17). LUZON ISLAND: NUEVA Vizcaya Province: Municipality of Quezon: Holotype (PNM 9566), Paratopotypes (PNM 9578-9582, KU 308865, 308866, 308900-308906, 308908, 308953).

Brachymeles orientalis (48). BOHOL ISLAND: BоноL Province: Municipality of Sierra Bullones: Holotype (CASSU 24436), Paratypes (CAS-SU 18702, 24428, 24434, 24437, 24458, 24442, 24446-24451, CAS 102404), (CASSU 25452, 25460); CAMIGUIN SUR ISLAND: CAMIGUIN Province: Municipality of Catarman: (CAS 110976110983); LEYTE ISLAND: LeYTe Province: Municipality of Baybay: (KU 311231-311235, 311241); MINDANAO ISLAND: Agusan Del Norte Province: Municipality of Cabadbaran: (CAS-SU 133301, 133616, 133749, 133752, 133754); SAMAR ISLAND: Eastern Samar Province: Municipality of Taft: (KU 305470, 310734-310736, 310739, 310942-310946, 310949, 310951, 310955).

Brachymeles paeforum (13). LEYTE ISLAND: LEYTE Province: Municipality of Burauen: Paratypes (CAS-SU 26110, 26112, 26115, 26120-26123); Municipality of Baybay City: Holotype (PNM 9746), Paratopotypes (KU 311224, 311225, 311224, PNM 9747, 9748).

Brachymeles pathfinderi (40). MINDANAO ISLAND: Sarangani Province: Municipality of Glan: (KU 324057324096).

Brachymeles samad (45). SAMAR ISLAND: EASTERN SAMAR Province: Municipality of Taft: Holotype (PNM 9767), Paratopotypes (KU 310730, 310731, 310820-310827, 310829-310839, 310928-310935, 310937, 310941); LEYTE ISLAND: LeYte Province: Municipality of Baybay City: Paratypes (KU 311216, 311218, 311220, 311221, 311223, PNM 9768-9775).

Brachymeles samarensis (7). SAMAR ISLAND: EASTERN 
SAMar Province: Municipality of Taft: (KU 310849310852, 311294-311296).

Brachymeles schadenbergi (34). BASILAN ISLAND: BASILAN Province: Municipality of Maluso: (CAS 60493); MINDANAO ISLAND: Misamis Occidental Province: (CAS-SU 23468, 23469, 23471, 23479-23481, 23484, 23485); Zamboanga del Norte Province: Municipality of Rizal: (CAS-SU 23494-23496); Zamboanga City: Municipality of Pasonanca: (KU 314967, 314969, 314970$314978, \quad 314980, \quad 314984, \quad 314985,314988-314992$, 314994, 314996, 314997).

Brachymeles suluensis (2). BASILAN ISLAND: BASILAN Province: Municipality of Isabela City: (CAS 60365, 60366).

Brachymeles talinis (31). NEGROS ISLAND: NegRos Oriental Province: Municipality of Valencia: Holotype (CAS-SU 18358), Paratype (CAS-SU 89813), (CAS 133871); Municipality of Dumaguete City: Paratype (CASSU 12225); Municipality of Siaton: (CAS-SU 22311, 22312; 22317, 22323); INAMPULAGAN ISLAND: Guimaras Province: Municipality of Sibunag: (CAS-SU 27972, 27996, 27997); PANAY ISLAND: ANTIQUE Province: Municipality of San Remigio: (KU 306756306760, 306762-306767, 306769, 306770-306776, 306786).

Brachymeles taylori (34). NEGROS ISLAND: Negros Occidental Province: Municipality of Silay City: (KU 324044-324056); Negros Oriental Province: Municipality of Valencia: Holotype (CAS-SU 18615), Paratypes (CAS-SU 18641, 18649, 18656, 18657, 18748), (CAS-SU 21873, 21877, 21880, 21883, 21884, 22355, 22356); CEBU ISLAND: CeBu Province: Municipality of Carcar: (CAS 154671, 154673, 154678-154682, 154686).

Brachymeles tiboliorum (3). MINDANAO ISLAND: SOUTH Cotabato Province: Municipality of Tampakan: Holotype (PNM 9777), Paratopotype (PNM 9776); Misamis Oriental Province: Municipality of Tubigan: Paratype (KU 326109).

Brachymeles tridactylus (20). NEGROS ISLAND: NeGros Occidental Province: Municipality of La Castellana: (CAS-SU 19424, 19426, 19427, 19429, 19452, 19458, 27082, 27083); Negros Oriental Province: Municipality of Manjuyod: Holotype (CAS-SU 18354); PANAY ISLAND: ANTIQUe Province: Municipality of Culasi: (KU 307726-307736).

Brachymeles tungaoi (12). MASBATE ISLAND: MASBATE Province: Municipality of Masbate City: Holotype (PNM 9722), Paratopotypes (KU 323934-323936); Municipality of Mobo: Paratypes (CAS 144229, 144230, 144290,
144306, 144307, 144313, 144341, 144342).

Brachymeles vermis (5). JOLO ISLAND: SUlu Province: Municipality of Jolo: Paratype (CAS-SU 62489), (CAS-SU 60720-60722, 60857).

Brachymeles vindumi (4). JOLO ISLAND: Sulu Province: Municipality of Jolo: Holotype (CAS 60724), Paratypes (CAS 60723, 60725, MCZ 26577).

Brachymeles vulcani (20). CAMIGUIN SUR ISLAND: Camiguin Province: Municipality of Mambajao: Holotype (PNM 9766), Paratypes (CAS-SU 26142, 26144-26146, 26165, 26166, 26184, 26185, 26231, 26236, 26294, 26295, CAS 139031); Municipality of Catarman: Paratypes (CASSU 28199, 28314, 28329, 28331, 28358, 28359).

Brachymeles wright (2). LUZON ISLAND: BENGUET Province: Municipality of La Trinidad: Holotype (MCZ 26589), (USNM 140756). 
APPENDIX II. Additional specimens examined for members of the genus Pseudogekko. Numbers in parentheses indicate the number of specimens examined. Several sample sizes are greater than those observed in the description due to the examination of subadult specimens which were excluded from morphometric analyses. All species examined are from the Philippines. Museum abbreviations for specimens examined follow those from Sabaj (2016).

Pseudogekko atiorum (16).--NEGROS ISLAND: NeGROS Occidental Province: Municipality of Cauayan (CASSUR 19372, 21122); Negros Oriental Province: Municipality of Valencia: Cuernos de Negros, Mt. Talinis (CAS 134292); Municipality of Sibulan (CAS 128956, 128959, 128963, 128971); Municipality of Valencia: Barangay Bongbong (PNM 9518 [holotype, formerly KU 302818], KU 327770, TNHC 62478); Municipality of Pamplona (CAS 138097, 145793, 147491); Municipality of Siaton (CAS 134269, CAS-SUR 26778); SIQUIJOR ISLAND: SiquiJor Province: Municipality of San Juan (CAS 145710).

Pseudogekko brevipes (7).-SAMAR ISLAND (SMF 8988 [holotype]); BOHOL ISLAND: BoHOL PROvince: Municipality of Sierra Bullones (CAS 131855, 147527, 147528, CAS-SU 24596, 25108, 25111).

Pseudogekko chavacano (4).- MINDANAO ISLAND: Zamboanga CiTY : Municipality of Zamboanga City (PNM 9812 [holotype, formerly KU 314963], KU 314964 [paratype]); Zamboanga del Norte Province: Cuot Creek (CAS-SU 23548, 23549).

Pseudogekko compresicorpus (12).-LUZON ISLAND: Laguna Province: Municipality of Los Baños: Barangay Batong Malake (KU 326434, 326436); Barangay Bagong Silang (KU 330735, 331657); Quezon Province: Municipality of Infanta: Barangay Magsaysay, InfantaMarikina Highway, Southern Sierra Madre Mountain Range (KU 334017, 344614-20); MASBATE ISLAND: Masbate Province: Municipality of Mobo (CAS 141560).

Pseudogekko cf. compresicorpus (1).-POLILLO ISLAND: Quezon Province: Municipality of Polillo; vicinity of Polillo Town (KU 326242).

Pseudogekko cf. compresicorpus (2).-LUZON ISLAND: Cagayan Province: Municipality of Gonzaga: Barangay Magrafil, Mt. Cagua (KU 330058).

Pseudogekko ditoy (3).--LEYTE ISLAND: Leyte Province: Municipality of Baybay: Barangay Gabas, Sitio Cienda (PNM 9811 [holotype, formerly KU 326437], KU 326438 [paratype]).

Pseudogekko isapa (16).--SIBUYAN ISLAND: RoMBLON Province: Municipality of Magdiwang: Barangay Tampayan, Mt. Guiting-Guiting Natural Park (PNM 9816 [holotype]), UPLB MNH-Z NS 4606-20; TABLAS
ISLAND: Romblon Province: Municipality of San Agustin (CAS 139713 [paratype]).

Pseudogekko pungkaypinit (6).-BOHOL ISLAND: BоноL Province: Municipality of Sierra Bullones: Barrio Dusita (CAS 131854 [paratype], CAS-SU 23655 [paratype]); Raja Sikatuna Natural Park (KU 324426 [paratype]); LEYTE ISLAND: LeYte Province: Municipality of Baybay (KU 326243 [paratype]); Barangay Guadalupe (PNM 9810 [holotype, formerly KU 326435]); MINDANAO ISLAND: Misamis Oriental Province: Municipality of Gingoog City: Barangay Lawaan, Sitio Kibuko, Mt. Lumot (KU 334019 [paratype]); SAMAR ISLAND: EASTERN SAMAR Province: Municipality of Balangiga, Barangay Guinmaayohan, Sitio Bangon, Kaantulan River Drainage (KU 344446-48).

Pseudogekko smaragdinus (35).-POLILLO ISLAND: QUEZON Province: Municipality of Polillo (KU 302819-302831, 303995-304002, 307638-307647, 326240, 326241, 331721); LUZON ISLAND: CAMARINeS DEL Norte Province: Municipality of Labo: Barangay Tulay Na Lupa (KU 313828).

Pseudogekko sumiklab (3).--LUZON ISLAND: ALBAY Province: Municipality of Tabaco: Barangay Mariroc, Sitio Nagsipit, Mt. Mayon: PNM 9843 (holotype); Sorsogon Province: Municipality of Irosin: Barangay Cawayan, Mt. Cawayan: KU 343847 (paratype); Municipality of Bulusan: Barangay Salvacion: KU 346543. 